\title{
Capacidade de inovar em STARTUPs: Uma abordagem sob a ótica da
}

\author{
orientação para aprendizagem
}

\author{
Innovativeness in STARTUPS: A learning-oriented approach
}

\author{
Marcos Luiz Lins Filho Doutor em Administração. Instituto Federal da Bahia (IFBA) - Brasil. marcos.lins@ifba.edu.br. \\ Adrianne Paula Vieira de Andrade Doutora em Administração. Universidade Federal do Rio Grande do Norte (UFRN) - Brasil. \\ adriannepaula@gmail.com. \\ Gilson Gomes da Silva Doutor em Administração. Universidade Federal do Rio Grande do Norte (UFRN) - Brasil. \\ gilsong@hotmail.com.
}

\begin{abstract}
Diante de um mercado cada vez mais competitivo, a inovação passa a ser um mantra do negócio. Isso é evidente no contexto das startups, empresas nascentes de base tecnológica que estão alterando modelos de negócios. Esse trabalho surge a partir da reflexão sobre antecedentes da capacidade de inovar em startups. $\mathrm{O}$ objetivo desse artigo é compreender como os elementos da aprendizagem organizacional contribuem para a capacidade de inovação das startups. A pesquisa é exploratória com abordagem qualitativa. Foram realizadas três entrevistas semiestruturadas. Para a análise dos dados foi utilizada a técnica de análise de conteúdo. Os resultados mostraram que o compartilhamento de conhecimentos intraorganizacionais, a mente aberta e o compromisso com a aprendizagem foram os aspectos mais evidenciados nas falas dos entrevistados. Foi destacada uma tendência de compartilhamento a partir do uso de métodos mais ágeis e interativos, como diálogos, interações informais por meio da difusão de conhecimentos no ecossistema colaborativo. Os empreendedores estão atentos a novas ideias, a lacunas do mercado e estimulam iniciativas dos funcionários que gerem inovações. A visão compartilhada foi o construto menos enfatizado nos relatos dos entrevistados.

Palavras-chave: Capacidade de Inovar. Startups. Inovação. Orientação para aprendizagem.
\end{abstract}

RESUMO

\begin{abstract}
In an increasingly competitive market, innovation becomes a mantra of businesses. This is evident in the context of startups, technology-based companies that are changing business models. This work is analysis of the ability to innovate in startups. The purpose of this paper is to understand how the elements of organizational learning contribute to innovation capacity of startups. The research is exploratory with a qualitative approach. Three semi-structured interviews were conducted. Data analysis was performed using the content analysis technique. The results showed that the intra-organizational knowledge sharing, openmindedness and commitment to learning were the most evident aspects in the statements of interviewees. Also, a trend for sharing through more agile and interactive methods, such as dialogues, informal interactions for the dissemination of knowledge in a collaborative ecosystem was identified. Entrepreneurs are attentive to new ideas and to market gaps, they also stimulate employees' initiatives that generate innovations. The shared vision was the least emphasized construct in the respondents' reports.
\end{abstract}

Keywords: Innovation. Startups. Innovativeness. Learning Orientation. 


\section{INTRODUÇÃO}

A dinamicidade, a competitividade e mudanças no ambiente externo impulsionam as organizações a gerarem inovação. Segundo Bucior, Gonçalo e Santos (2015), as organizações são constantemente provocadas a desenvolver novos produtos e serviços para gerar oportunidades em mercados atuais e em novos mercados.

A inovação muitas vezes é percebida como uma forma de construir e sustentar vantagem competitiva, todavia a inovação não deve ser vista apenas sob essa perspectiva. A inovação está ligada aos processos internos da organização de modo que a geração de uma inovação depende dos recursos organizacionais, das rotinas, do gerenciamento (TIDD; BESSANT, 2015).

Em ambientes de negócios altamente competitivos que tem produtos com ciclo de vida curtos como é o caso da indústria de software, é fundamental inovar continuamente (EDISON; TORKAR; BIN ALI, 2013). As empresas que têm a tecnologia como o produto final tendem a enxergar a inovação como um mantra do negócio.

Neste contexto, estão inseridas as startups as quais são empresas formadas por pessoas, construída em diferentes ramos que surge espontaneamente na condição de extrema incerteza, tem a inovação no seu núcleo para criar produtos e serviços que pretendem revolucionar o mercado (RIES, 2011). Segundo Paradkar, Knight e Hansen (2015), as startups bem-sucedidas, competem com empresas rivais, alteram os padrões tradicionais de consumo e criam benefícios para os clientes ou melhoram significativamente os existentes.

O número dessas startups aumenta gradativamente, segundo levantamento feito através do site StartupBase, que atua como base de dados oficial do ecossistema brasileiro de Startups, a quantidade de startups já ultrapassa o número de 12 mil empresas cadastradas na base (CARRILO, 2019). Em um ambiente altamente competitivo, startups têm um papel importante. Elas são constituídas por jovens empresários dispostos a assumir riscos com ideias disruptivas e criativas que criam negócios e podem ajudar a revigorar a economia de um país (MORONI; ARRUDA; ARAÚJO, 2015). Diante da expansão desse segmento, é importante estudar como a inovação se manifesta nessas empresas.

A inovação pode ser estudada como uma capacidade organizacional. Segundo Edison, Torkar e Bin Ali (2013), as organizações necessitam de meios não só para medir sua produção inovadora, mas também para avaliar a sua capacidade de inovação. A capacidade de inovar é a capacidade da empresa de lidar com a inovação, introduzindo novos processos, produtos ou ideias na organização. Esse conceito é um dos mais importantes fatores que podem impactar no desempenho das organizações (HULT; HURLEY; KNIGHT, 2004).

A capacidade de inovar tem despertado a atenção dos pesquisadores nacionais e internacionais os quais tem estudado essa temática sob diferentes óticas. Dentre esses estudos, percebe-se que grande parte deles tem abordado a influência da capacidade de inovar no desempenho das organizações (MARTínEZROMAN et al., 2015; WOODSIDE, 2005; YANG, 2012) .

Enquanto é geralmente aceito que a inovação contribui para o desempenho da organização, relativamente pouco se sabe sobre os condutores de inovação (HULT; HURLEY; KNIGHT, 2004). Valladares, Vasconcellos e Serio (2014) destacam a necessidade de mais estudos sobre a capacidade de inovação. Além disso, existem poucos estudos que analisam a capacidade de inovar de startups.

De acordo com Prajogo e Ahmed (2006), entre os muitos estudos sobre inovação, duas grandes correntes de pesquisa podem ser identificados: um fluxo examina a inovação em termos de aspectos tecnológicos os quais enfatizam a importância da tecnologia e pesquisa e desenvolvimento para a inovação (LEBLANC et al., 1997; ZAWISLAK et al., 2012), o outro fluxo estuda a influência dos fatores humanos, enfatizando aspectos como estrutura organizacional e cultura e pressupõe que as pessoas e contexto organizacional são os principais determinantes de inovações de sucesso (COOPER; KLEINSCHMIDT, 1995; AKGÜN et al., 2007; CALANTONE; CAVUSGIL; ZHAO, 2002).

A capacidade de inovar será analisada a partir da perspectiva da orientação para aprendizagem. Estudos anteriores mostraram que a orientação para aprendizagem está relacionada com a inovação e reforça a capacidade de inovar das organizações (CALANTONE; CAVUSGIL; ZHAO, 2002; HULT; HURLEY; KNIGHT, 2004; AKGÜN et al., 2007). 
Calantone, Cavusgil e Zhao (2002) defendem que uma organização comprometida com a aprendizagem é mais provável a ser comprometida com a inovação, usa a tecnologia em inovações; aproveita as oportunidades criadas pelos mercados porque tem a capacidade de compreender e antecipar as demandas dos clientes, e também é provável que a organização que tenha uma maior capacidade de inovação do que os concorrentes.

A partir de uma base conceitual da orientação para aprendizagem, o artigo busca dar resposta à pergunta de pesquisa: "Como os elementos da aprendizagem organizacional contribuem para a capacidade de inovar em startups?". De posse da questão de pesquisa, definiu-se como objetivo geral analisar a contribuição dos elementos da aprendizagem organizacional para a capacidade das startups em introduzir produtos e serviços inovadores no mercado.

Os resultados do estudo estão organizados em quatro sessões além desta introdução. Na segunda sessão é apresentado o referencial teórico, com os principais autores e estudos que servirão de embasamento teórico para a realização da pesquisa. A terceira sessão apresenta a metodologia utilizada nesta pesquisa, abordando o tipo da pesquisa, sujeitos de pesquisa, coleta de dados, o instrumento da coleta de dados e a forma como os dados foram analisados. A quarta seção apresenta os resultados da pesquisa e a análise dos dados. Na quinta sessão, são dispostas as considerações finais. E, por fim, têm-se as referências que foram utilizadas para a elaboração do presente trabalho.

\section{REFERENCIAL TEÓRICO}

\subsection{Orientação para Aprendizagem}

O entendimento do conceito de orientação para aprendizagem (OA) parte da compreensão da aprendizagem organizacional (VIEIRA, 2015). Segundo Fiol e Lyles (1985), a aprendizagem organizacional está relacionada ao processo de aperfeiçoamento das ações através de um melhor conhecimento e entendimento das informações presentes no contexto organizacional.

Neste sentido, a orientação para aprendizagem refere-se às características que uma organização possui para utilizar suas habilidades e práticas de forma a promover uma maior facilidade nos processos de aprendizagem organizacional, permitindo que toda a organização aprenda (JEREZ-GÓMEZ; CÉSPEDESLORENTE; VALLE-CABRERA, 2005). A OA busca expandir a visão de aprendizagem organizacional para um contexto mais amplo, onde a organização tem noção das suas habilidades e assume uma postura mais aberta, fazendo uso das suas habilidades para promover esse ambiente de aprendizado.

Segundo Fiol e Lyles (1985), embora exista um consenso com relação ao papel estratégico da aprendizagem organizacional no desempenho das organizações, não há um modelo amplamente aceito pela academia. O trabalho apresentado por Simon (1969 apud FIOL; LYLES, 1985) mostra uma aparente distinção entre dois conceitos de aprendizagem. O primeiro, direcionado para o desenvolvimento de insights e mudanças de estado do conhecimento. O segundo, com foco em mudanças estruturais e seus resultados na organização.

Nota-se que existe uma diversidade de abordagens para o estudo dessa temática. Sinkula, Baker e Noordewier (1997) afirmam que alguns autores acreditam que a mudança de comportamento é necessária para a aprendizagem (FIOL; LYLES, 1985), outros atribuem exclusivamente a uma nova forma de pensar (HUBER, 1991) e a necessidade de compartilhamento de modelos mentais, da visão organizacional e da postura aberta a novas abordagens para solução de problemas (SENGE, 1990).

No entanto, o consenso existente entre os pesquisadores é de que a aprendizagem organizacional contribui para o desempenho das organizações. Nesta ótica, há que se atribuir um olhar mais estratégico, voltado para explorar as habilidades da organização em transformar aprendizado e conhecimento em vantagem competitiva (SLATER; NARVER, 1995).

Logo, o conceito de aprendizagem organizacional mudou para uma perspectiva de orientação para aprendizagem, em que a empresa faz uso das suas competências e habilidades para obter vantagem competitiva (SLATER; NARVER, 1995). Essa tendência inicia-se na concepção do aprendizado em ciclo único 
proposta por Argyris e Schön (1997) e que inaugura uma fase em que o conhecimento é obtido a partir de uma aprendizagem exploradora e com base nas percepções já existentes.

Na segunda fase, a aprendizagem é obtida pela organização a partir da aquisição de capacidades diferenciadas das percepções já existentes. Nessa fase, o processo exploratório visa a descoberta e a inovação. Argyris e Schön (1997) definem essa etapa como aprendizagem em ciclo-duplo. Na aprendizagem em cicloduplo, há um questionamento das normas e valores existentes, com o objetivo de se promover um novo olhar e, consequentemente, incentivar comportamentos e atitudes inovadoras na organização (PERIN et al., 2006).

Com base nessa nova perspectiva, alguns autores afirmam que a OA faz parte de um aspecto cultural da empresa (HULT; HURLEY; KNIGHT, 2004). Sinkula, Baker e Noordewier (1997) reforçam a ideia que a OA se dá a partir dos próprios membros da organização, que assumem o papel de agentes de aprendizagem e mudanças. O conceito é fundamentado no que os autores apresentam como três facilitadores pertencentes aos valores do núcleo organizacional: comprometimento com o aprendizado, visão compartilhada e mente aberta.

Nesse estudo, optou-se por utilizar o conceito de OA proposto por Sinkula, Baker e Noordewier (1997) que define a $\mathrm{OA}$ como um conjunto de valores organizacionais que influenciam o quanto a empresa torna-se propensa a criar e usar o conhecimento para agir de forma proativa. A adoção desse conceito foi baseada na ideia de associação feita pelos autores entre a influência de um conjunto de valores organizacionais na propensão em assumir uma postura proativa por parte da empresa. Baseado nesse conceito, a OA assume um papel de agente influenciador da capacidade de inovar equiparando-se à compreensão que se busca a partir da pesquisa.

\subsection{Capacidade de Inovar}

Na literatura são encontrados diversos conceitos para capacidade de inovar. No entanto, há uma aparente confusão entre este e o conceito de inovação, talvez pelo fato do segundo ser um conceito mais estudado na literatura. Um dos conceitos mais difundidos é o de Schumpeter (1934) o qual defende que a inovação se refere a novas combinações de recursos já existentes para produzir novos produtos, ou produtos antigos de uma forma mais eficiente ou para acessar novos mercados.

A inovação proposta na teoria schumpeteriana, considera fundamentais os seguintes elementos: novos produtos; novos mercados; novos processos; diferenciação; novas estruturas de mercado; novas fontes de fornecimento de matérias-primas; novos mecanismos de distribuição; novos empreendedores, isto é, novos empresários; entre outros (TAVARES; KRETZER; MEDEIROS, 2005). Para Garcia e Calantone (2002), os termos radical, realmente novo, incrementais e descontínuo são usados para definir inovação.

Covin e Slevin (1989) apresentam uma conceituação para a capacidade de inovar, afirmando que esta é a propensão de uma empresa para a inovação. É uma tendência da empresa de participar e apoiar novas ideias, novidade, experimentação e processos criativos que podem resultar em novos produtos, serviços ou processos tecnológicos (LUMPKIN; DESS, 1996).

A capacidade de inovar é definida por Hurley e Hult (1998) como a capacidade que uma organização possui para introduzir novas ideias, processos e produtos com sucesso no mercado. Garcia e Calantone (2002) reforçam esse conceito afirmando ser o potencial de uma empresa em gerar uma mudança de paradigma do ponto de vista científico e tecnológico ou mercadológico.

Nota-se que nos trabalhos recentes, a capacidade de inovar está ligada ao uso do conhecimento e habilidades como forma de aprendizagem, mas também ao da orientação para o mercado visando sempre a obtenção de uma vantagem competitiva.

Autores definem a capacidade de inovar não só a partir de uma perspectiva puramente organizacional. Para Lawson e Samson (2001) a capacidade de inovar é vista como uma capacidade de integração de ordem superior, isto é, a capacidade de moldar e gerenciar múltiplas capacidades tanto organizacionais, como habilidades e conhecimentos ligados as pessoas. Os autores ainda enfatizam a capacidade de gerir essa integração como sendo o principal fator para que uma empresa tenha sucesso no estímulo à inovação. 
Para Hogan et al. (2011) a capacidade de inovar faz parte de um processo de integração do conhecimento coletivo, das habilidades e recursos da empresa para realização de atividades voltadas para inovações técnicas (produtos e/ou serviços e processos) e não técnicas (gestão, mercado e comercialização).

\subsection{Estudos sobre a Orientação para Aprendizagem e a Capacidade de Inovar}

Estudos recentes evidenciam que a orientação para aprendizagem está ligada à capacidade da organização em utilizar seus conhecimentos e habilidades de forma a implementar novas ideias, processos e produtos no mercado (HURLEY; HULT, 1998). Tal fato é corroborado pela literatura, pois há um aparente consenso entre os pesquisadores que a OA possui um papel estratégico importante na capacidade de inovação.

Calantone, Cavusgil e Zhao (2002), definiram a OA como a atividade de criação e uso do conhecimento com o objetivo de obter uma vantagem competitiva para a organização através da capacidade de inovar. A OA contempla quatro dimensões: compromisso com a aprendizagem, visão compartilhada, mente aberta e compartilhamento do conhecimento intraorganizacional. A base para a criação do modelo foi o trabalho de Sinkula, Baker e Noordewier (1997), porém os autores sugerem uma nova dimensão de compartilhamento de conhecimento intraorganizacional por acreditarem que a OA não se torna efetiva sem que haja um sistema eficiente para o compartilhamento do conhecimento.

Ainda seguindo a visão de que a OA influencia a capacidade de inovar das organizações, o estudo de Hult, Hurley e Knight (2004) assume que a OA faz parte da cultura organizacional. Com base no conceito apresentado por Huber (1991) os autores associam a OA ao desenvolvimento de novos conhecimentos ou ideias que têm o potencial de influenciar o comportamento por meio de seus valores e crenças dentro da cultura da organização.

Jerez-Gomez, Céspedes-Lorente e Valle-Cabrera (2005) aproximam a OA da capacidade de inovar e se referem a OA como sendo a capacidade de uma organização para processar conhecimento utilizando suas habilidades e práticas de forma a criar, adquirir, transferir e integrar conhecimentos para modificar o seu comportamento. Os autores atribuem quatro condições para que o desenvolvimento da OA se torne efetiva: compromisso gerencial, perspectiva de sistemas (consciente coletivo), abertura e experimentação e transferência de conhecimento e integração.

O estudo de Lee e Tsai (2005) avalia as relações entre a orientação para o marketing e a orientação para aprendizagem com a capacidade de inovar de 700 empresas no setor industrial e de serviços em Taiwan. Os autores concluem que a ênfase maior na OA está associada a maiores níveis de inovação das empresas e que um ambiente colaborativo, com maior participação e compartilhamento pode aumentar a capacidade de uma empresa promover inovação e melhorar o desempenho dos negócios.

Rhee, Park e Lee (2010) identificaram os direcionadores da capacidade de inovar, bem como os efeitos de mediação da OA. O estudo foi conduzido com 333 empresas de pequeno porte da área de tecnologia na Coréia do Sul. Os resultados revelaram que a OA afeta significativamente a capacidade de inovar das empresas e que os gestores devem enfatizar a OA a fim de impulsionar a inovação e, consequentemente, obter melhor desempenho.

Apesar dos pesquisadores reconhecerem que a OA possui um papel estratégico importante na capacidade de inovação, ainda não há um modelo único aceito pela academia que explique a relação entre a OA e capacidade de inovar e observa-se dimensões variadas entre os construtos dos estudos (CALANTONE; CAVUSGIL; ZHAO, 2002; HULT; HURLEY; KNIGHT, 2004; JEREZ-GÓMEZ; CÉSPEDES-LORENTE; VALLE-CABRERA, 2005; LEE; TSAI, 2005; KESKIN, 2006; ONAĞ; TEPECl; BAŞALPA, 2014). Neste estudo, assumimos o conceito de capacidade de inovar proposto por Calantone, Cavusgil e Zhao (2002). O conceito é aderente ao contexto de startups, por se tratar de um modelo de empresa nascente que tem seus projetos vinculados fortemente à pesquisa para desenvolvimento de ideias inovadoras.

Nas startups, as pessoas, com seus conhecimentos e habilidades, assumem um papel importante em todo o processo de desenvolvimento de novos produtos e/ou serviços. Dessa forma, a capacidade de inovar 
dessas empresas pode ser o elemento de base para geração de novas ideias para produtos e serviços que irão atender as demandas do mercado e que devem, necessariamente, fazer parte do dia a dia da organização.

O modelo teórico utilizado na pesquisa assume que a OA é antecedente da capacidade de inovar. $\mathrm{O}$ construto da OA utiliza as quatro dimensões propostas por Calantone, Cavusgil e Zhao (2002). A figura 1 apresenta o modelo teórico.

Figura 1 - Modelo teórico adotado na pesquisa

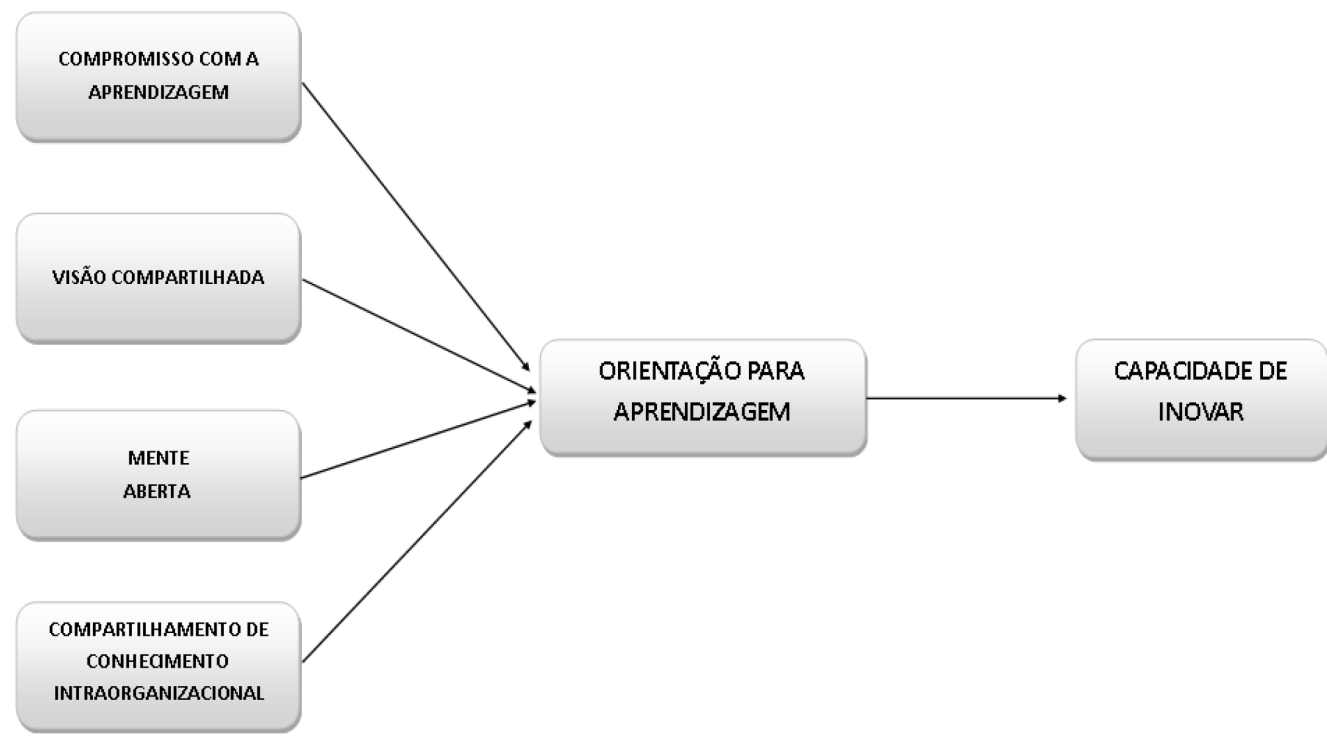

Fonte: Adaptado de Calantone, Cavusgil e Zhao (2002).

\section{METODOLOGIA}

A pesquisa é exploratória visto que busca explorar o fenômeno da capacidade de inovar no contexto de startups, o que ainda é pouco investigado na literatura acadêmica. Trata-se de uma pesquisa qualitativa básica, uma vez que busca compreender as vivências, percepções e experiências dos empreendedores. $\mathrm{O}$ interesse dos pesquisadores refere-se a entender como as pessoas interpretam e atribuem significado as suas experiências e constroem seus mundos (MERRIAM; TISDELI, 2016).

Para a seleção dos sujeitos da pesquisa, utilizamos uma amostragem não probabilística. Os sujeitos foram selecionados com base no tempo, localização, disponibilidade dos entrevistados (MERRIAM; TISDELL, 2016). Para a seleção, buscamos empreendedores que criaram uma Startup no Rio Grande do Norte. Inicialmente, fizemos uma lista com dez empreendedores. Em seguida, entramos em contato com eles via $e$ maile telefone e conseguimos a participação de três empreendedores. O Quadro 1 apresenta as startups que participaram da pesquisa.

Quadro 1 - Características das startups analisadas

\begin{tabular}{|l|l|l|l|l|}
\hline Caso & Inovação & Entrevistado & $\begin{array}{l}\text { Ano de } \\
\text { criação }\end{array}$ & $\begin{array}{l}\text { Participação em } \\
\text { programas de } \\
\text { Incubação/Aceleração }\end{array}$ \\
\hline Startup A & $\begin{array}{l}\text { Sistema de inteligência de } \\
\text { negócio }\end{array}$ & $\begin{array}{l}\text { Capitalista de } \\
\text { risco }\end{array}$ & 2013 & Não \\
\hline Startup B & Método de ensino educacional & Fundador & 2008 & Em processo de incubação \\
\hline Startup C & $\begin{array}{l}\text { Solução para tomada de } \\
\text { decisões em empresa de varejo }\end{array}$ & Cofundador & 2013 & Em processo de aceleração \\
\hline
\end{tabular}

Fonte: Elaboração própria (2018). 
É importante destacar que todas as startups pesquisadas foram criadas recentemente e incorporam a Tecnologia da Informação (TI) em seus processos e produtos finais. Uma delas está no segundo ano do processo de incubação, outra está no primeiro ano de um programa de aceleração e a outra não participa de nenhum desses programas.

Para a coleta de dados foram realizadas entrevistas semiestruturadas associada à foto-elicitação. Essa técnica foi utilizada para estimular a memória dos entrevistados e possibilitar que o informante seja capaz de explicar e identificar o conteúdo daquela fotografia, demonstrando ao entrevistador o seu conhecimento sobre o objeto pesquisado (COLLIER; COUCEIRO; FERRAZ, 1973; MERRIAM; TISDELL, 2016).

Elaboramos um roteiro prévio com três questões abertas relacionadas ao assunto pesquisado, as quais foram as seguintes: (i) Você considera a sua empresa inovadora?; (ii) Qual é a inovação presente nos seus produtos/ serviços?; (iii) O que essa foto representa para a sua empresa?

Para a última pergunta, selecionamos quatro fotografias no Google Imagens as quais podem ser visualizadas nas figuras 2 e 3 . A primeira foto da figura 2 retratra o ambiente de trabalho nas startups e foi utilizada para representar o construto "compartilhamento de conhecimentos intraorganizacional". A segunda foto destaca o alinhamento e o comprometimento da equipe e foi selecionada para representar o construto "compromisso com a aprendizagem".

Figura 2 - Primeiras Fotos usadas nas entrevistas - Parte 1

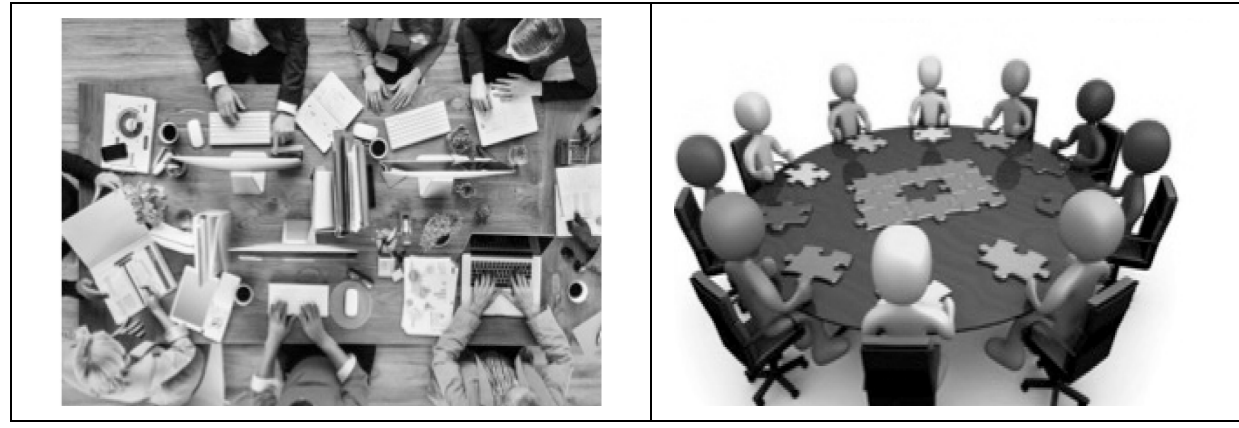

Fonte: Google (2016).

A primeira foto da figura 3 foi selecionada para representar o construto "mente aberta". A segunda foto representa a "visão compartilhada" e foi utilizada para estimular os empreendedores a expressarem a sua opinião sobre a visão de diferentes pessoas e da equipe nas atividades da Startup.

Figura 3 - Fotos usadas nas entrevistas - Parte 2

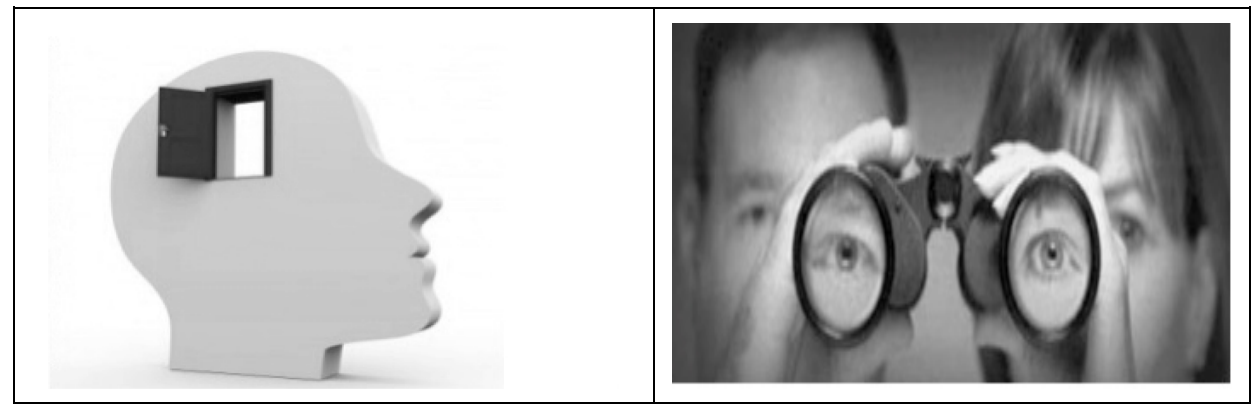

Fonte: Google (2016).

Antes da efetiva coleta de dados, foi realizada uma entrevista piloto com um empreendedor que atua no segmento de TI. Com base nessa entrevista foi feita a validade de face do roteiro utilizado. Foram realizados ajustes no roteiro e uma das fotos foi alterada, pois percebeu-se que a mesma não gerava uma boa representação da dimensão. As entrevistas foram realizadas pelos três pesquisadores nos escritórios das 
empresas, sendo que uma foi realizada em um espaço de convivência da Universidade Federal do Rio Grande do Norte. A duração das entrevistas foi de 20 a 40 minutos.

Ao iniciar a entrevista, foram disponibilizados os termos de confidencialidade e de consentimento e foi solicitado aos entrevistados a permissão para a gravação. As entrevistas foram transcritas seguindo as especificações de Flick (2009) o que resultou em 20 páginas de transcrição. É importante ressaltar que o processo de coleta, transcrição e análise foi cíclico de modo que assim que as entrevistas eram finalizadas, já eram transcritas e analisadas.

Para a análise dos dados, utilizamos a técnica de análise de conteúdo. Esta técnica é composta por três fases: a pré-análise, que consiste na organização, sistematização e transcrição dos dados; a exploração do material e o tratamento dos resultados que engloba o processo de codificação e categorização; a inferência e a interpretação que consistirá nas análises comparativas (BARDIN, 2011).

Para apoiar esta análise, utilizamos o software Atlas TI. Esse software auxilia o processo de análise qualitativa de dados (Merriam \& Tisdell, 2016). O uso desse software possibilitou a triangulação entre os pesquisadores permitindo que os autores gerenciassem o processo de análise e a checagem dos resultados por pares durante o processo de codificação (BANDEIRA DE MELLO; SILVA; GODOI, 2000).

$\mathrm{Na}$ fase de pré-análise, foi realizada uma leitura prévia do material e a sistematização das ideias. $\mathrm{Na}$ fase de exploração do material iniciou-se o processo de codificação. A primeira codificação realizada foi a codificação da entrevista piloto. Essa codificação serviu como um exercício para os pesquisadores. À medida em que era realizada a leitura da entrevista, foram identificados segmentos, criados códigos e conectado os segmentos aos códigos representativos. Foi criada uma lista de códigos para esses primeiros códigos criados.

Em seguida, foi feita a codificação das três entrevistas. A primeira etapa foi a codificação inicial em que foram gerados aproximadamente 200 códigos. Essa codificação foi feita detalhadamente e linha a linha (GIBBS, 2009). O segundo ciclo de codificação foi a focalizada. Nesta etapa, fizemos uma revisão dos códigos e optouse por excluir os que não estavam ligados às dimensões da teoria estudada. É importante ressaltar que no processo de validação dos códigos criados pelos pesquisadores constatou-se convergências para os mesmos trechos e com uma descrição similar. Os códigos que estavam relacionados ao problema de pesquisa foram mantidos o que levou a uma redução para 19 códigos.

$\mathrm{Na}$ terceira etapa, vinculamos esses códigos as suas respectivas famílias ou categorias. Nesta etapa, utilizamos a categorização baseada no conceito que um modelo é construído usando fontes semelhantes de inspiração representando um arranjo hierárquico dos códigos em potencial (GIBBS, 2009). O quadro 2 mostra as categorias criadas, a quantidade de códigos gerados e de trechos codificados.

Quadro 2 - Categorias criadas

\begin{tabular}{|l|c|c|}
\hline Categorias conceituais & Códigos & $\begin{array}{c}\text { Trechos } \\
\text { codificados }\end{array}$ \\
\hline Compartilhamento de conhecimentos intraorganizacional & 7 & 18 \\
\hline Compromisso com a aprendizagem & 4 & 8 \\
\hline Mente aberta & 6 & 9 \\
\hline Visão compartilhada & 2 & 5 \\
\hline
\end{tabular}

Fonte: Elaboração própria (2018).

A última fase da análise de conteúdo foi a inferência e interpretação dos resultados. Nessa fase, foi feita uma análise reflexiva e crítica dos achados, utilizou-se esquemas gráficos (netview) (BANDEIRA DE MELLO; SILVA; GODOI, 2000).

No que concerne aos critérios de qualidade e rigor na pesquisa qualitativa, procurou-se satisfazer os critérios de credibilidade, transferibilidade, confiança e confirmabilidade especificados por Godoy (2005). Para alcançar a credibilidade dos nossos resultados, utilizou-se a triangulação de pesquisadores. Durante toda a pesquisa realizou-se sessões de questionamento dos pares destinadas a explorar e refletir sobre os passos metodológicos e práticos do estudo. 
Em relação a transferibilidade, foram apresentados todos os procedimentos metodológicos e passos utilizados. Para atender ao critério de confiança, foram feitos registros durante todas as etapas do processo e uma espécie de auditoria por uma pesquisadora qualitativa que analisou os resultados, as inferências realizadas, a apropriabilidade das categorias desenvolvidas e as conclusões alcançadas. Foi feito um acompanhamento com essa pesquisadora que emitiu feedbacks durante todo o processo de pesquisa. A realização dessa auditoria também atende ao critério de confirmabilidade (GODOY, 2005).

\section{RESULTADOS E DISCUSSÕES}

A figura 4 apresenta os resultados da pesquisa de forma a exibir uma rede de relações entre as dimensões estudadas e os códigos criados. 
Figura 4 - Hierarquia de codificação da pesquisa

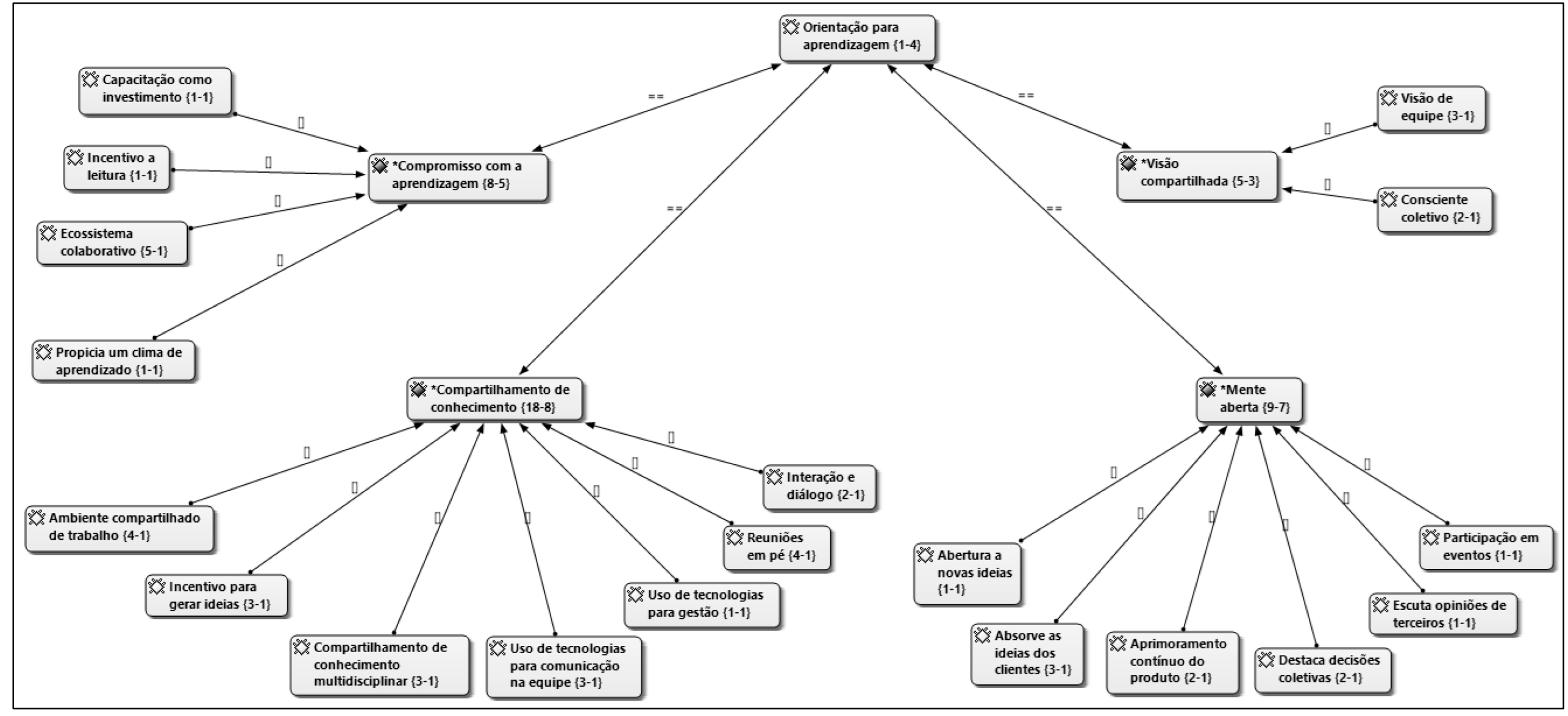

Fonte: Resultados da pesquisa (2018). 


\subsection{Compartilhamento do Conhecimento}

Essa categoria foi a mais evidenciada na fala dos entrevistados, foram gerados sete códigos com 18 citações. Esse construto remete para processos e rotinas utilizados na difusão de conhecimento dentro do ambiente organizacional. A figura 5 mostra os códigos criados.

Figura 5 - Compartilhamento do conhecimento como antecedente da capacidade de inovar

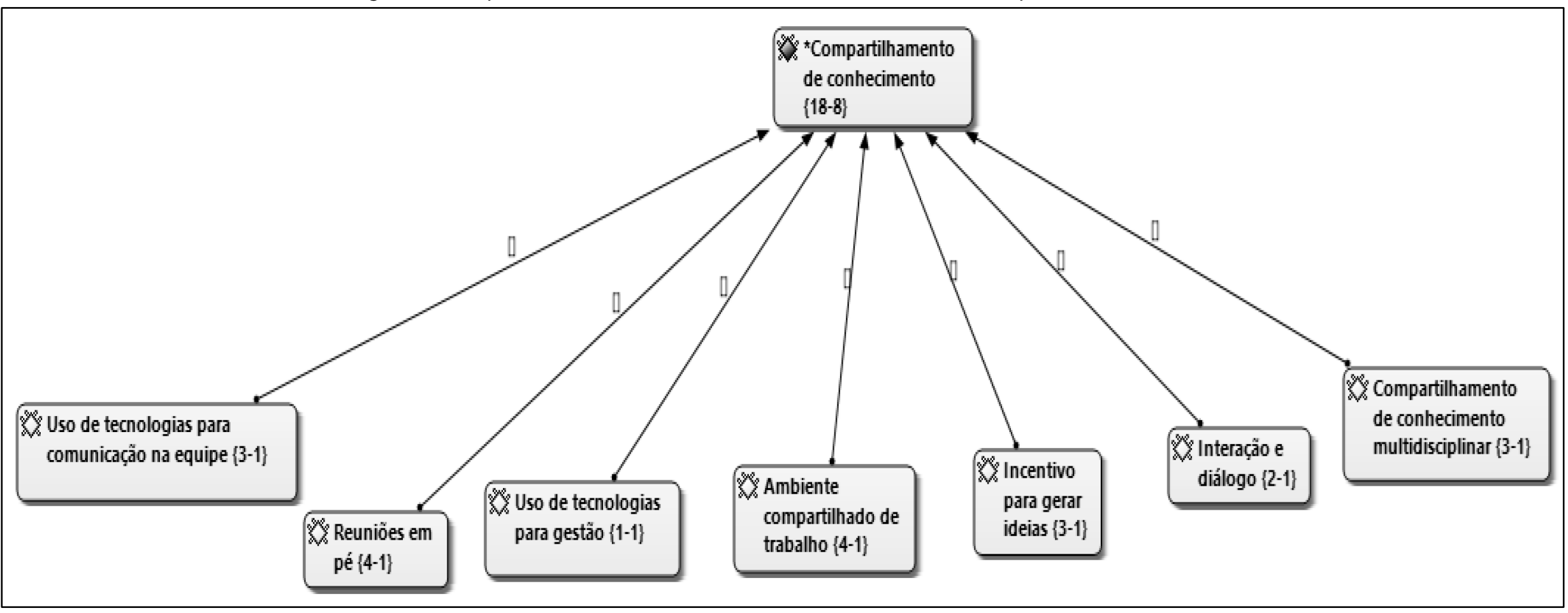

Fonte: Resultados da pesquisa (2018). 
Nos relatos dos entrevistados foi constatada uma tendência de compartilhamento do conhecimento a partir do uso de métodos mais ágeis e interativos, corroborando com as ideias apresentadas por Akgün et al. (2007) que sugerem o uso de comunicações informais, conversas, diálogos e interação entre os indivíduos para uma melhor difusão do conhecimento interno. A adoção de reuniões rápidas e em pé tem sido uma das formas utilizadas pelas startups para promover esse dinamismo. Os trechos abaixo, retirados das falas dos entrevistados, demonstram tal fato:

Todas as reuniões semanais são de no máximo 20 minutos, eu acho que reunião que passa de meia hora é totalmente improdutiva, e eu falo porque já vivenciei reuniões de duas a três horas (Startup C).

Olha uma das características aqui da empresa é tentar fazer reuniões em pé (Startup A).

Ainda sobre a incorporação de práticas que promovam um maior diálogo e interação, os relatos citam a tomada de decisão de forma conjunta e a adoção de ambientes compartilhados de trabalho, como forma de aproximar as pessoas e tornar o processo mais interativo criando a sensação de proximidade. Os relatos abaixo retratam essas questões.

Como a empresa sempre nasceu com muitos sócios, é, isso de colaboração, trocar ideias até chegar uma decisão final (Startup B)

Exatamente para tornar as reuniões mais dinâmicas, nós queremos ter menos tempo, ser mais dinâmicos nessas reuniões para que você tenha mais tempo para tomar as ações. Então esse cenário aqui não seria comum aqui na empresa por exemplo, mas é muito interessante você ver que são pessoas que tão até trabalhando, trabalhando num local compartilhado [...] Eu acho que é exatamente para promover uma sensação de interação similar a essa aqui, das pessoas estarem do lado da outra e elas terem ideias em conjunto (Startup A).

Nesse aspecto, o ambiente de startups incorpora uma nova visão ao compartilhamento de conhecimento. Os estudos de Calantone, Cavusgil e Zhao (2002) e Akgün et al. (2007) evidenciam a necessidade de integração e compartilhamento de conhecimento baseado num modelo organizacional descentralizado e dividido em departamentos/setores. Jerez-Gomez, Céspedes-Lorente e Valle-Cabrera (2005) ratificam a ideia do compartilhamento do conhecimento de forma restrita a um olhar interno da organização e focada unicamente nos atores presentes nesse ambiente.

Todos os empreendedores entrevistados citaram a colaboração como fonte de conhecimento e, consequentemente, como semente para inovação. $O$ aspecto colaborativo está associado a adoção de ambiente compartilhado de trabalho dentro da empresa e, em especial, a experiência promovida a partir de ambientes de coworking, incubação de empresas e participação em eventos. Segundo os relatos dos entrevistados, essa troca agrega conhecimentos multidisciplinares. Os trechos que seguem mostram a importância desse ambiente de colaboração interno e externo.

Todo mundo trabalha muito junto por que [...] Assim é o lance colaborativo da coisa, mesmo eu não sendo desenvolvedor eu estou lá acompanhando o desenvolvimento pra entender se a funcionalidade criada ou a tela criada tem uma interação legal, porque sou eu que me relaciono com o cliente, eu tenho que repassar isso para os desenvolvedores. A gente trabalha com uma sinergia muito grande (Startup C).

E lá a gente trabalha no ambiente de coworking que não necessariamente eu só interajo com a minha empresa. Na verdade, eu interajo com mais doze startups que são aceleradas no mesmo lugar e que cada um tem um background diferente, tem gente com perfil empreendedor muito melhor que o meu, com muito mais experiência que eu e vem somando. Então, essa colaboração existe dentro da empresa e de quem está no mesmo ambiente mesmo não sendo da empresa (Startup C).

Com relação a adoção de ferramentas tecnológicas para gestão do conhecimento e para comunicação entre pares, foram criados 2 códigos com 4 citações. Os códigos identificados reforçam as afirmações de Calantone, Cavusgil e Zhao (2002) e Akgün et al. (2007) de que o compartilhamento de conhecimento depende do uso de ferramentas tecnológicas. Os autores afirmam que o conhecimento deve 
ser capturado, armazenado de forma estruturada e compartilhado de forma útil para que possa gerar resultados.

Ratificando a teoria, na fala de um dos entrevistados é relatado o uso de ferramenta computacional para controle e gestão de atividades de forma a compartilhar e manter uma base de conhecimento. Um segundo entrevistado cita o uso de ferramentas para comunicação entre os membros da equipe para compartilhamento de informações.

\section{O acompanhamento que a gente faz é via trello e etc, usando essas ferramentas de gestão de atividades (Startup C).}

A gente usa tecnologias atuais de comunicação entre a equipe (Startup B).

\subsection{Mente Aberta}

A categoria mente aberta foi identificada na fala dos entrevistados como um importante antecedente da capacidade de inovar. Foram gerados seis códigos e nove trechos codificados. Essa categoria representa a vontade dos empreendedores de avaliar criticamente a rotina operacional da organização, buscar e aceitar novas ideias. A figura 6 mostra os códigos criados.

Figura 6 - Mente Aberta

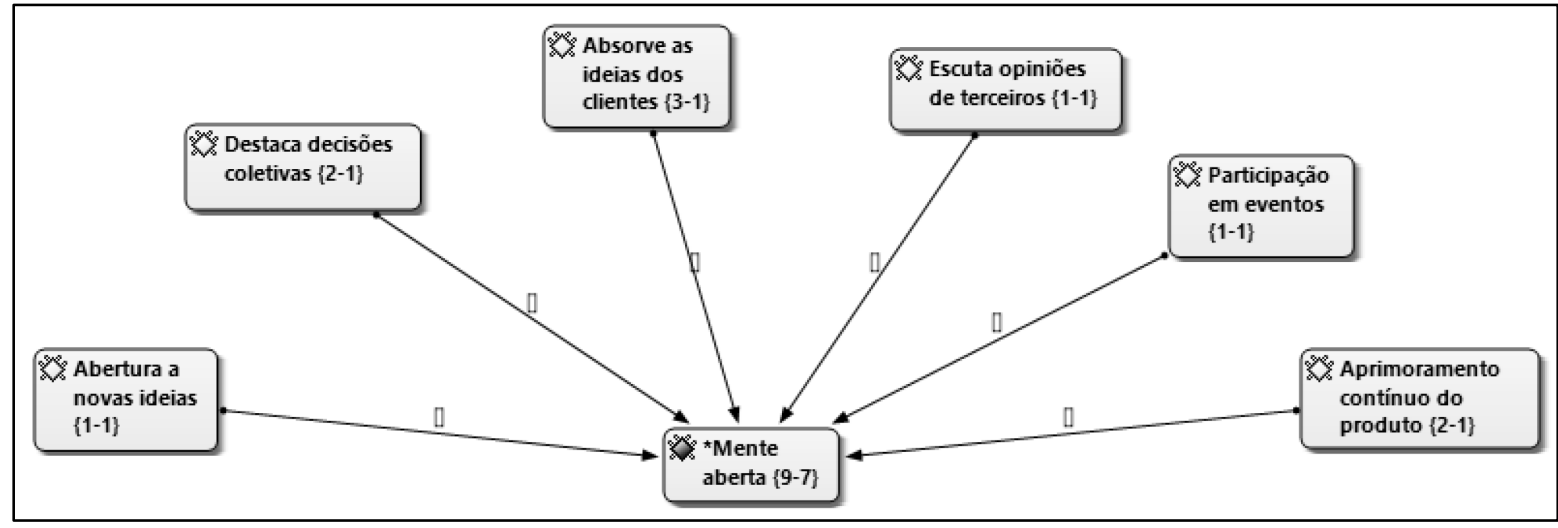

Fonte: Resultados da pesquisa

Foi observada na análise um anseio por parte dos empreendedores em avaliar criticamente a rotina operacional da organização e buscar novas ideias, de acordo com as ideias de Akgün et al. (2007) que ajudam a convencer a adoção de novos produtos. Também foi citada a participação em eventos como um aspecto determinante para os empreendedores expandirem seus horizontes, visualizarem novos mercados e buscarem ideias.

A abertura a novas ideias tem sido uma das formas utilizadas pelas startups para obter inovação dentro da organização. As falas dos entrevistados abaixo demonstram isso:

É para questão de inovação, de peculiaridades, coisa diferentes, acho que é perfeitamente o que a gente faz, tanto nossos serviços como nossos produtos ele está evoluindo (Startup B).

É você ter sempre a sua cabeça aberta para novas ideias. Aquilo que, se você não escuta, aqui a gente tem, aqui e nas outras empresas que eu estou envolvido com esses trabalhos todos, o objetivo é você ter uma, você sempre poder ouvir outras opiniões. (Startup A).

Os relatos evidenciam a evolução constante no produto como consequência das necessidades dos clientes e a adoção de decisões coletivas, como forma de tentar entender essas necessidades a partir de vários 
pontos de vista. A fala do empreendedor da Startup C mostra a importância atribuída as opiniões e ideias dos clientes.

Eu não mando na empresa e não sou eu que falo quais as funcionalidades que a gente vai desenvolver. A gente sabe que quem manda na empresa são os clientes e o que ele fala que é útil é útil. Pode ser genial, surgir uma ideia de dentro, genial e isso daí a gente colocou muito na cultura, tanto na equipe de desenvolvimento e tal, pode ser genial essa ideia, mas não desenvolva uma linha de código até que o cliente fale eu quero isso. E não é que o cliente fale: é legal! É: eu quero! Eu pago por isso! (Startup C).

\subsection{Compromisso com a Aprendizagem}

A categoria compromisso com a aprendizagem também recebeu ênfase por parte dos entrevistados. Foram criados quatro códigos que abordam elementos intrínsecos do compromisso com a aprendizagem nessas organizações associados a oito trechos. Foram associados quatro códigos a essa categoria, os quais foram: "incentivo a leitura", "propicia um clima de aprendizado", "capacitação como investimento" e "ecossistema colaborativo" conforme pode ser visto na Figura 7.

Figura 7 - Compromisso com a aprendizagem

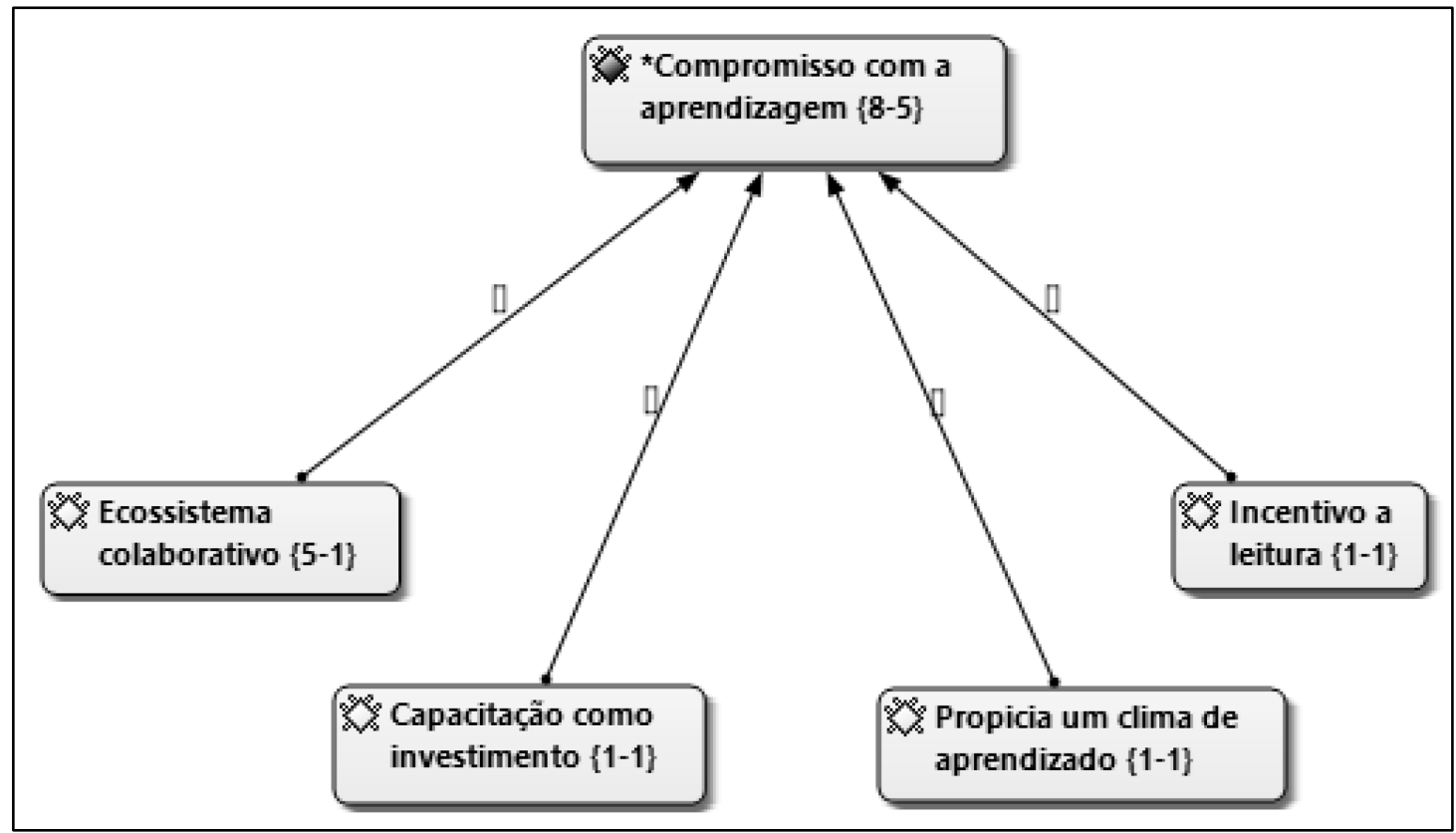

Fonte: Resultados da pesquisa (2018).

O código "Incentivo a leitura" emergiu na fala do empreendedor da Startup A o qual acredita que a inovação pode ser gerada a partir da leitura e da imaginação. Ele mostra que é importante incentivar os seus funcionários a ler e a despertar a imaginação para que isso possa gerar inovação.

É então, ela só vem com conhecimento né, fazer com que desperte nas pessoas a vontade e tentar também promover a cultura e ler, conhecer e saber. Você, você, quando você ler, isso desperta a sua imaginação. A imaginação ela é um carvão ativado para gerar inovação (Startup A).

O código "propicia um clima de aprendizado" representa a preocupação do empreendedor da Startup A em desenvolver um ambiente propício para aquisição, criação e transferência de conhecimento. Ele expõe em sua fala: "Olha, inovação acho que ela ela éé, acaba vindo naturalmente de um ambiente. Tem que promover dentro do ambiente aquele aah, vamos dizer assim, as condições propícias para que ela aconteça". 
O entrevistado demonstra em sua fala a importância de promover um clima de aprendizado dentro da sua Startup. Esse achado corrobora com Calantone, Cavusgil e Zhao (2002) o qual constatou que um clima positivo de aprendizagem é benéfico para as empresas que aspiram se destacar através de desenvolvimento de produtos.

Outro código que emergiu no relato do gestor da Startup C foi a "capacitação como investimento". Nesse código, fica clara a percepção do empreendedor da Startup C da aprendizagem dos funcionários como um investimento e não como uma despesa. O entrevistado relatou que realiza investimentos em cursos mesmo que não estejam relacionados a atividade principal da Startup, pois acredita que a aprendizagem do funcionário pode contribuir para o aprimoramento do produto e/ou serviço gerado.

O código "ecossistema colaborativo" foi muito enfatizado na fala do gestor da Startup $C$ o qual destacou a influência do ecossistema em que a Startup está inserida na aprendizagem da organização. É importante destacar que essa Startup faz parte de um programa de aceleração. Esse código reflete o ambiente colaborativo presente na aceleradora. O empreendedor da Startup C relatou que tanto ele como os seus funcionários aprendem constantemente com outras startups que também são aceleradas e acabam trazendo e incorporando inovações ao produto que é desenvolvido. Isso pode ser visto no seu relato a seguir.

\begin{abstract}
Cara, a rede! A rede né?! A aceleradora lá, a gente tá num lugar que foi considerado o melhor ecossistema de startups do Brasil. Então, por si só a comunidade startup já se ajuda. Só que para ter um ecossistema como um todo você tem que ter vários outros players (....). Então, tipo, a galera lá tem muita gente boa e aí você fala: P**! Você aprende muito ali na convivência, no café, no ping pong, no cigarro (rsrsrs). Você vai aprendendo sabe?! (Startup C)
\end{abstract}

Esse código não foi enfatizado pelas outras startups pesquisadas o que parece mostrar que essa é uma característica específica de startups que estão vinculadas a uma aceleradora.

\title{
4.4 Visão Compartilhada
}

Dentre as categorias analisadas, a visão compartilhada foi a que teve uma menor ênfase e uma menor quantidade de códigos associados. Essa categoria representa uma identidade comum que os funcionários têm em torno da organização (JEREZ-GÓMEZ; CÉSPEDES-LORENTE; VALLE-CABRERA, 2005).

Conforme pode ser visto na figura 8 foram criados os códigos: "visão da equipe" e "consciente coletivo".

Figura 8 - Visão compartilhada como antecedente da capacidade de inovar

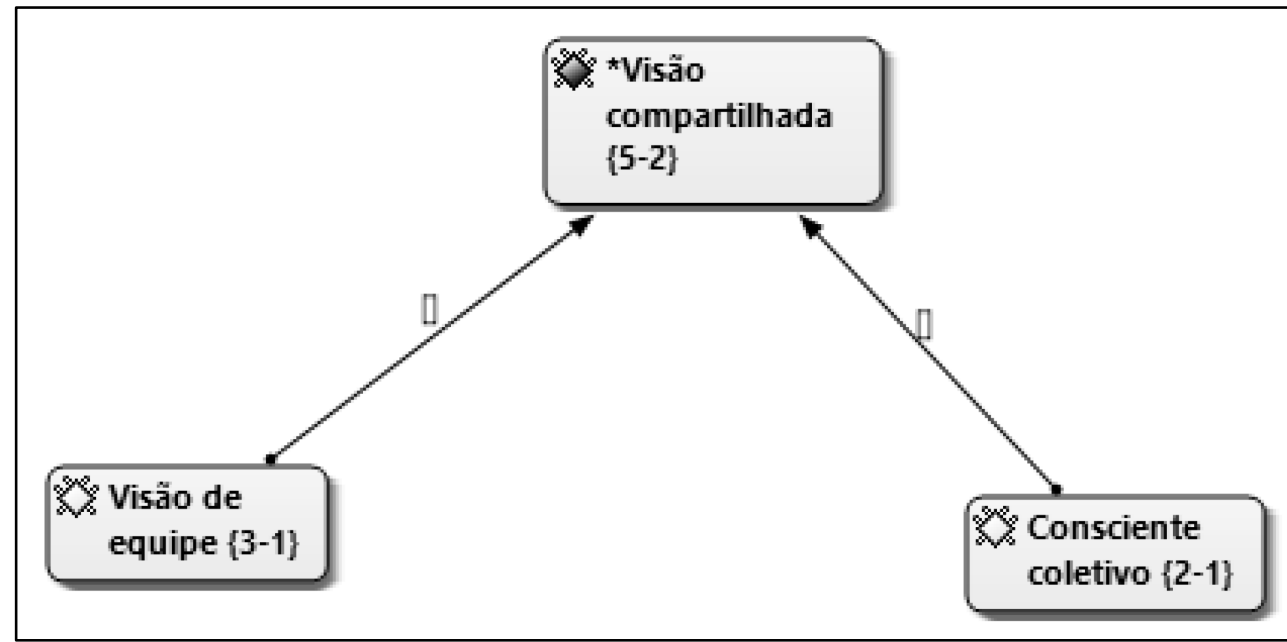

Fonte: Resultados da pesquisa (2018). 
O código "visão da equipe" foi criado a partir dos relatos dos empreendedores da Startup C e Startup A os quais ressaltaram a importância de diferentes visões e perspectivas para atrair novas ideias e gerar inovação. Os empreendedores mostram que a inovação gerada quase sempre é fruto da reunião de diferentes opiniões e ideias das pessoas que compõem a equipe da Startup. Isso pode ser visualizado nos trechos a seguir.

Eu acho que ninguém inova sozinho, minto, você tinha situações científicas, cientistas que, sei lá um Graham Bell alguém muito brilhante pra isso. Mas eu acredito que a melhor forma de inovar é inovar em grupo. E você poder ter, você ter várias pessoas, e provavelmente a forma mais rápida de inovar seja em grupo (Startup $\mathrm{A}$ ).

O outro código associado a esse constructo foi "Consciente coletivo" o qual foi evidenciado na fala de Antônio e representa a importância do alinhamento dos objetivos e da visão dos funcionários com o objetivo da Startup, ou seja, os funcionários precisam acreditar no objetivo da Startup e se engajar para alcançá-lo de modo que todos na organização estejam direcionados ao objetivo global. Antônio relata que esse consciente coletivo é algo determinante da contratação e manutenção dos funcionários na Startup. Isso pode ser visto a seguir:

Então hoje eu prefiro, um cara mais limitado tecnicamente, mas que tenha visão ou de alguma maneira ele tem a predisposição de ter a nossa visão e comprar o nosso sonho porque tecnicamente ele se capacita, agora eu não vou entrar na cabeça do cara para falar: Olha o certo é isso! Até porque eu não sou o dono da verdade, mas pra a Startup Alpha tem que ter um alinhamento de visão, um alinhamento ali de ritmo de trabalho etc [...] (Startup C).

Esse achado corrobora com Akgün et al. (2007) o qual constatou que o conhecimento que os funcionários têm a respeito dos objetivos da empresa, ou seja, o fato deles estarem bem cientes de como elas contribuem para atingir os objetivos globais tem um impacto sobre a capacidade de inovar das empresas.

\subsection{Análise Intercasos}

Essa análise possibilita um entendimento e exploração mais profunda dos casos analisados além de auxiliar na generalização dos resultados. Essa abordagem considera um caso como uma abordagem única, olhando as configurações, associações, causas e efeitos entre os casos (Miles \& Huberman, 1994).

Os casos aqui investigados são as startups. O quadro 3 expõe os códigos que foram associados aos relatos dos entrevistados para cada uma das dimensões analisadas juntamente com a quantidade de citações associada a cada um deles.

\begin{tabular}{|c|c|c|c|}
\hline \multicolumn{4}{|c|}{ Quadro 3 - Análise intercasos } \\
\hline $\begin{array}{c}\text { Categorias da } \\
\text { capacidade de } \\
\text { inovar }\end{array}$ & Startup A & Startup B & Startup C \\
\hline $\begin{array}{l}\text { Compartilhamento } \\
\text { de conhecimentos }\end{array}$ & $\begin{array}{l}\text { Reuniões em pé (1 } \\
\text { citação) } \\
\text { Ambiente } \\
\text { compartilhado de } \\
\text { Trabalho (1 citação) } \\
\text { Incentivo para gerar } \\
\text { ideias (1 citação) } \\
\text { Interação e diálogo } \\
\text { (1 citação) }\end{array}$ & $\begin{array}{l}\text { Ambiente } \\
\text { compartilhado de } \\
\text { trabalho (1 citação) } \\
\text { Uso de tecnologias } \\
\text { para comunicação na } \\
\text { equipe (1 citação) } \\
\text { Interação e diálogo } \\
\text { (1 citação) }\end{array}$ & $\begin{array}{l}\text { Ambiente compartilhado de } \\
\text { trabalho ( } 2 \text { citações) } \\
\text { Incentivo para gerar ideias ( } 2 \\
\text { citações) } \\
\text { Reuniões em pé (3 citações) } \\
\text { Uso de tecnologias para } \\
\text { comunicação na equipe ( } 2 \\
\text { citações) }\end{array}$ \\
\hline
\end{tabular}




\begin{tabular}{|c|c|c|c|}
\hline & & & $\begin{array}{l}\text { Uso de tecnologias para } \\
\text { gestão (1 citação) }\end{array}$ \\
\hline Mente aberta & $\begin{array}{l}\text { Abertura a novas } \\
\text { ideias (1 citação) } \\
\text { Destaca decisões } \\
\text { coletivas (1 citação) } \\
\text { Escuta opiniões de } \\
\text { terceiros (1 citação) } \\
\text { Participação em } \\
\text { eventos (1 citação) }\end{array}$ & $\begin{array}{l}\text { Aprimoramento } \\
\text { contínuo do produto ( } 2 \\
\text { citações) } \\
\text { Destaca decisões } \\
\text { coletivas (1 citação) }\end{array}$ & $\begin{array}{l}\text { Absorve ideias dos clientes ( } 3 \\
\text { citações) }\end{array}$ \\
\hline $\begin{array}{l}\text { Compromisso com a } \\
\text { aprendizagem }\end{array}$ & $\begin{array}{l}\text { Incentivo à leitura } \\
\text { (1 citação) } \\
\text { Propicia um clima } \\
\text { de aprendizado (1 } \\
\text { citação) }\end{array}$ & - & $\begin{array}{l}\text { Capacitação como } \\
\text { investimento (1 citação) } \\
\text { Compartilhamento de } \\
\text { conhecimento } \\
\text { multidisciplinar (3 citações) } \\
\text { Ecossistema colaborativo (5 } \\
\text { citações) }\end{array}$ \\
\hline Visão compartilhada & $\begin{array}{l}\text { Visão de equipe ( } 1 \\
\text { citação) }\end{array}$ & - & $\begin{array}{l}\text { Consciente coletivo ( } 2 \\
\text { citações) } \\
\text { Visão de equipe ( } 2 \text { citações) }\end{array}$ \\
\hline
\end{tabular}

Fonte: Elaboração própria (2018).

Em relação ao construto Compartilhamento de Conhecimento é possível perceber que o código "ambiente de trabalho compartilhado" foi evidenciado pelos três empreendedores das três startups o que mostra que a forma da estruturação do trabalho e a execução das atividades diárias parece contribuir com a capacidade de inovar. Os códigos Interatividade e diálogo, Uso de tecnologias de comunicação e Reuniões em pé emergiram nos relatos de duas Startups.

No que concerne ao construto mente aberta, percebe-se que cada empreendedor associou diferentes elementos a essa categoria. Duas startups mencionaram as decisões coletivas como um aspecto que parece contribuir para a geração de ideias e aprimoramento de atividades. A Startup A destacou a importância da opinião de terceiros e a participação em eventos de empreendedorismo. A Startup B evidenciou uma forte orientação ao cliente, as suas opiniões e as suas preferências para gerar inovações na forma do seu serviço.

No construto Compromisso com a aprendizagem percebe-se que não houve uma uniformidade de códigos entre os empreendedores. O empreendedor da Startup C destacou o compartilhamento do conhecimento interdisciplinar e o ecossistema colaborativo como condutores da inovação. $\mathrm{O}$ empreendedor da Startup A destacou o incentivo a leitura e o clima de aprendizado como elementos que disseminam a aprendizagem na organização.

O construto Visão compartilhada foi o menos evidenciado pelos três empreendedores. Duas startups citaram a importância da visão da equipe nas rotinas e atividades da organização o que pode contribuir para a geração de inovação. 


\section{CONSIDERAÇÕES FINAIS}

Os resultados obtidos nesta pesquisa evidenciaram os construtos compartilhamento de conhecimentos intraorganizacionais, mente aberta e compromisso com a aprendizagem como os mais citados e, portanto, os que mais contribuem para a capacidade de inovar dessas startups.

Em relação ao compartilhamento de conhecimentos intraorganizacionais, foi destacada uma tendência de compartilhamento a partir do uso de métodos mais ágeis e interativos, como diálogos, interações informais e também emergiu uma nova visão ao compartilhamento de conhecimento em startups que é o aspecto do ambiente colaborativo no qual estas empresas estão inseridas e se desenvolvem.

O compromisso com a aprendizagem se faz presente na visão dos empreendedores que buscam incentivar a leitura e criar um clima de aprendizado dentro das empresas. Outro aspecto importante relatado foi a visão da capacitação como investimento mesmo não estando diretamente ligada as atividades da empresa. Entre os empreendedores de startups há uma abertura e atenção permanentes a novas ideias e lacunas do mercado. A partir dessa postura, os empreendedores buscam conduzir, da melhor forma, o aprimoramento contínuo do produto e/ou serviço para atender as demandas dos clientes. Percebeu-se uma mudança na visão desses empreendedores, que passam a absorver as ideias dos clientes e de terceiros como parte do processo de inovação.

No que diz respeito a visão compartilhada, esse foi o construto menos enfatizado nos relatos dos entrevistados. Porém, destacou-se a importância da visão de equipe para inovação e do consciente coletivo em busca de um maior engajamento dos funcionários com os objetivos e "sonhos" da empresa.

No contexto das startups, ficou evidente que a OA está ligada a capacidade de inovar das empresas, em especial, pelo fato das startups possuírem características voltadas para o uso de novos modelos de compartilhamento de conhecimento e comunicação entre os seus funcionários, clientes e parceiros. Tal fato, favorece a criação de novos conhecimentos e, consequentemente, gera novas ideias para produtos e serviços.

A pesquisa apresentou como principal fator limitante, o número de entrevistados. A partir dos relatos dos entrevistados percebeu-se que a visão de inovação dos empreendedores possui forte influência do ambiente no qual estão inseridas suas startups, bem como do papel do líder (empreendedor) na inserção da inovação no dia a dia da empresa. No entanto, devido à pequena quantidade de entrevistados, não foi possível capturar todos elementos presentes a partir dessa visão. A falta de diversidade da amostra também contribuiu como fator limitante da pesquisa a partir da percepção do grupo de que há perfis diferenciados de empreendedores de startups e que a pesquisa teve de se limitar ao perfil dos 3 entrevistados.

Por ter um caráter exploratório, a pesquisa examinou de forma preliminar a influência da OA na capacidade de inovar de startups. Como sugestões de trabalhos futuros, sugere-se avaliar o comportamento da OA e da capacidade de inovar em startups após um período de maturação ou após lançamento do produto ou serviço. Recomenda-se também um estudo conjunto entre a OA e demais orientações presentes na literatura para compreender suas influências na capacidade de inovar; a realização de estudos longitudinais para compreender o efeito do ambiente colaborativo na capacidade de inovar.

Por fim, do ponto de vista teórico, a pesquisa exploratória trouxe como contribuição preliminar a compreensão de que no contexto das startups, assim como nas outras empresas, há uma influência da OA como antecedente a capacidade de inovar. Como contribuição metodológica, o uso da fotoelicitação, para compor a entrevista, contribuiu no processo de coleta e análise de dados e promoveu uma interação mais criativa por parte do entrevistado, tornando-se uma alternativa para validar a percepção do entrevistado. Em termos práticos, a pesquisa serve como fonte de informação para os empreendedores de startups identificarem que dimensões da OA são mais importantes para a capacidade de inovar da empresa.

\section{REFERÊNCIAS}

AKGÜN, A. E. et al. Emotional and learning capability and their impact on product innovativeness and firm performance. Technovation, v. 27, n. 9, p. 501-513, Sept. 2007. 
ARGYRIS, C.; SCHÖN, D. A. Organizational learning: a theory of action perspective. Reis: Revista española de investigaciones sociológicas, n. 77, p. 245-350, 1997.

BANDEIRA DE MELLO, R.; SILVA, A. B.; GODOI, C. K. Pesquisa qualitativa em estudos organizacionais: paradigmas, estratégias e métodos. São Paulo: Editora Saraiva, 2000.

BARDIN, L. Análise de conteúdo. São Paulo: Edições 70, 2011.

BESSANT, J.; TIDD, J.; PAVITT, K. Gestão da Inovação. 3. ed. Porto Alegre: Bookman, 2008.

BUCIOR, E. R.; GONÇALO, C. R.; SANTOS, A. M. D. In: A INFLUÊNCIA DA CAPACIDADE DE INOVAR NO DESEMPENHO ORGANIZACIONAL EM EMPRESAS DE TECNOLOGIA DE INFORMAÇÃO COM ATUAÇÃO NACIONAL E INTERNACIONAL, 39., Belo Horizonte. Anais [...]. Belo Horizonte: ANPAD, 2015.

CALANTONE, R. J.; CAVUSGIL, S. T.; ZHAO, Y. Learning orientation, firm innovation capability, and firm performance. Industrial marketing management, v. 31, n. 6, p. 515-524, Sept. 2002.

CARRILO, Ana Flávia. Crescimento das startups: veja o que mudou nos últimos cinco anos! [2019]. Disponível em: https://abstartups.com.br/crescimento-das-startups/. Acesso em: 13 mar. 2020.

COLLIER, J.; COUCEIRO, S. M.; FERRAZ, I. Antropologia visual: a fotografia como método de pesquisa. São Paulo: EDUSP, 1973.

COOPER, R. G.; KLEINSCHMIDT, E. J. Benchmarking the Firm's Critical Success Factors in New Product Development. Journal of Product Innovation Management, v. 12, n. 5, p. 374-391, Nov. 1995.

COVIN, J. G.; SLEVIN, D. P. Strategic management of small firms in hostile and benign environments. Strategic Management Journal, v. 10, n. 1, p. 75-87, Jan./Feb. 1989.

EDISON, H.; TORKAR, R.; BIN ALI, N. Towards innovation measurement in the software industry. Journal of Systems and Software, v. 86, n. 5, p. 1390-1407, May 2013.

FIOL, M. C.; LYLES, M. A. Organizational learning. Academy of Management Review, v. 10, n. 4, p. 803-813, Oct. 1985.

FLICK, U. Introdução à pesquisa qualitativa. 3. ed. Porto Alegre: Artmed, 2009.

GARCIA, R.; CALANTONE, R. A critical look at technological innovation typology and innovativeness terminology: a literature review. Journal of Product Innovation Management, v. 19, n. 2, p. 110-132, March 2002.

GIBBS, G. R. Análise de dados qualitativos. Porto Alegre: Artmed, 2009.

GODOY, A. S. Refletindo sobre critérios de qualidade da pesquisa qualitativa. Gestão.Org - Revista Eletrônica de Gestão Organizacional, v. 3, n. 2, p. 80-89, maio/ago. 2005.

GOOGLE. Google Imagens. Google, 2016. Disponivel em: www.google.com.br. Acesso em: 10 out. 2016.

HOGAN, S. J. et al. Reconceptualizing professional service firm innovation capability: Scale development. Industrial Marketing Management, v. 40, n. 8, p. 1264-1273, Nov. 2011.

HUBER, G. P. Organizational learning: the contributing processes and the literatures. Organization Science, v. 2, n. 1, p. 88-115, Feb. 1991. 
HULT, G. T. M.; HURLEY, R. F.; KNIGHT, G. A. Innovativeness: Its antecedents and impact on business performance. Industrial Marketing Management, v. 33, n. 5, p. 429-438, July 2004.

HURLEY, R. F.; HULT, G. T. M. Innovation, market orientation, and organizational learning: an integration and empirical examination. Journal of Marketing, v. 62, n. 3, p. 42-54, July 1998

JEREZ-GÓMEZ, P.; CÉSPEDES-LORENTE, J.; VALLE-CABRERA, R. Organizational learning capability: a proposal of measurement. Journal of Business Research, v. 58, n. 6, p. 715-725, June 2005.

KESKIN, H. Market orientation, learning orientation, and innovation capabilities in SMEs: an extended model. European Journal of Innovation Management, v. 9, n. 4, p. 396-417, 2006.

LAWSON, B.; SAMSON, D. Developing Innovation Capability in Organisations: A Dynamic Capabilities Approach. International Journal of Innovation Management, v. 5, n. 3, p. 377-400, Sept. 2001.

LEBLANC, L. J. et al. A comparison of US and Japanese technology management and innovation. International Journal of Technology Management, v. 13, n. 5-6, p. 601-614, 1997.

LEE, T.-S.; TSAI, H.-J. The effects of business operation mode on market orientation, learning orientation and innovativeness. Industrial Management \& Data Systems, v. 105, n. 3, p. 325-348, Apr. 2005.

LUMPKIN, G. T.; DESS, G. G. Clarifying the entrepreneurial orientation construct and linking it to performance. Academy of Management Review, v. 21, n. 1, p. 135-172, Jan. 1996.

MARTÍNEZ-ROMAN, J. A. et al. Innovativeness and business performances in tourism SMEs. Annals of Tourism Research, v. 54, p. 118-135, Sep. 2015.

MERRIAM, S. B.; TISDELL, E. J. Qualitative research: a guide to design and implementation: revised and expanded from qualitative research and case study applications in education. 4th. ed. São Francisco: JosseyBass, 2016.

MILES, M. B.; HUBERMAN, A. M. Qualitative data analysis: an expanded sourcebook. 2nd. ed. [S.I.]: Sage Publications, 1994.

MORONI, I.; ARRUDA, A.; ARAÚJO, K. The Design and Technological Innovation: How to Understand the Growth of Startups Companies in Competitive Business Environment. Procedia Manufacturing, v. 3, p. 2199 2204, 2015.

ONAğ, A. O.; TEPECI, M.; BAşALPA, A. A. Organizational Learning Capability and its Impact on Firm Innovativeness. Procedia - Social and Behavioral Sciences, v. 150, p. 708-717, Sept. 2014.

PARADKAR, A.; KNIGHT, J.; HANSEN, P. Innovation in start-ups: Ideas filling the void or ideas devoid of resources and capabilities? Technovation, v. 41-42, n. 1, p. 1-10, July/Aug. 2015.

PERIN, M. G. et al. Processo de aprendizagem organizacional e desempenho empresarial: o caso da indústria eletroeletrônica no Brasil. RAE Eletrônica, v. 5, n. 2, jul./dez. 2006.

PRAJOGO, D. I.; AHMED, P. K. Relationships between innovation stimulus, innovation capacity, and innovation performance. R\&D Management, v. 36, n. 5, p. 499-515, Nov. 2006.

RHEE, J.; PARK, T.; LEE, D. H. Drivers of innovativeness and performance for innovative SMEs in South Korea: Mediation of learning orientation. Technovation, v. 30, n. 1, p. 65-75, Jan. 2010. 
RIES, E. The Lean Startup: How Today's Entrepreneurs Use Continuous Innovation to Create Radically Successful Businesses. New York: Crown Business, 2011.

SCHUMPETER, J. The theory of Economic Development: An Inquiry into Profits, Capital, Credit, Interest and the Business Cycle. 1. ed. Cambridge: Harvard University Press, 1934. 255 p.

SENGE, P. M. A Quinta Disciplina: arte, teoria e prática da organização de aprendizagem. São Paulo: Nova Cultural, 1990.

SINKULA, J. M.; BAKER, W. E.; NOORDEWIER, T. A framework for market-based organizational learning: Linking values, knowledge, and behavior. Journal of the Academy of Marketing Science, v. 25, n. 4, p. 305, Sept. 1997.

SLATER, S. F.; NARVER, J. C. Market orientation and the learning. Journal of Marketing, v. 59, n. 3, p. 63-74, July 1995.

TAVARES, P. V.; KRETZER, J.; MEDEIROS, N. Economia Neoschumpeteriana: expoentes evolucionários e desafios endógenos da indústria brasileira. Revista Economia Ensaios, v. 20, n. 1, 2005.

TIDD, J.; BESSANT, J. Gestão da Inovação. 5. ed. Porto Alegre: Bookman, 2015.

VALLADARES, P. S. D. D. A.; VASCONCELLOS, M. A. D.; SERIO, L. C. D. Capacidade de Inovação: Revisão Sistemática da Literatura. Revista de Administração Contemporânea, Curitiba, v. 18, n. 5, p. 598-626, set./out. 2014

VIEIRA, M. H. Os motivos da relação entre orientação para aprendizagem e performance. 2015. Dissertação (Mestrado em Administração) - Pontifícia Universidade Católica do Rio Grande do Sul (PUCRS), Porto Alegre, 2015.

WOODSIDE, A. G. Firm orientations, innovativeness, and business performance: Advancing a system dynamics view following a comment on Hult, Hurley, and Knight's 2004 study. Industrial Marketing Management, v. 34, n. 3, p. 275-279, Apr. 2005.

YANG, J. Innovation capability and corporate growth: An empirical. Journal of Engineering and Technology Management, v. 29, n. 1, p. 34-46, Jan./Mar. 2012.

ZAWISLAK, P. A. et al. Innovation Capability: From Technology Development to Transaction Capability. Journal of Technology Management \& Innovation, v. 7, n. 2, p. 14-27, July 2012. 